\title{
Deadbeat PQ Control for Islanded Smart Grids
}

\author{
Ehab Bayoumi, Mostafa Soliman, Hisham Soliman
}

\begin{abstract}
The dynamic performance of smart (micro)grids depends on the proper selection of the controller gains and power-sharing parameters. This manuscript describes the control design to achieve a deadbeat desirable performance in terms of: i) Zero steady-state error. ii) Minimum rise time. iii) Minimum settling time. iv) Less than $2 \%$ overshoot/undershoot This paper considers an Islanded microgrid system composed of two distributed generation (DG) units. Each DG unit includes three-phase pulse width modulation (PWM) inverter. The proposed controllers are proportional- integral (PI) type. The Controllers gains of the inverters and the Phase Locked Loop (PLL) parameters are designed to guarantee deadbeat dynamic performance in terms of minimal overshoot and system stability. The Particle Swarm Optimization (PSO) is used to tune the controller parameters of the current, PQ loops, and the PLL. The proposed controllers are compared with the traditional (Ziegler and Nichols), auto-tuned, and interiorpoint methods to shows the excellence of the proposed technique. Results authenticate and endorse the effectiveness of the proposed controllers and PLL design technique to achieve the desired deadbeat response of the study microgrid system.
\end{abstract}

Index Terms - microgrids, particle swarm optimization, distributed generation, renewal energy resources, droop control.

\section{INTRODUCTION}

Currently, renewable energy systems such as photovoltaic arrays (PVs), fuel cells, microturbines, small hydrogeneration plants and wind energy have vast development in distributed generation (DG) systems. Several aspects are forcing this development: (1) to enhance economic profits, and reliability, and (2) to reduce environmental pollution problems and global warming gas emission [1]-[3]. A microgrid is a distribution system composed of a group of DG units and local loads. A microgrid should be able to operate either in grid-connected mode or in islanded mode [4]. Therefore, the microgrid systems must be capable to afford stable operation in both modes.

The droop characteristics of the DGs is commonly used to control the microgrid systems. The droop controls that are applied in synchronous generators and reactive power sharing can also be used in the application of PWM inverter in DGs [5]-[8]. The implementation of the droop control depends on the PWM inverter control structure. There are two main types for the PWM inverter controls for DG: active-reactive power (PQ) or voltage-frequency (VF). Each

Published on September 23, 2020.

Ehab Bayoumi, Electrical and Electronics Engineering Department, University of Eswatini, Eswatini

(corresponding e-mail: ehab.bayoumi@gmail.com)

Mostafa Soliman, Electrical Power Engineering Department, Cairo University, Egypt.

Hisham Soliman, Department of Electrical and computer engineering, Sultan Qaboos University, Oman. type has its droop control implementation. In PQ control the voltage-frequency (VF) droop characteristic method is used, whereas in VF control the active-reactive (PQ) droop characteristic method is used [9]-[11]. In [12] it is shown that the controller coefficient of the power-sharing and the load demand has a great effect in the low-frequency modes of operation, whereas the controller parameters of the inner and outer loop and the loop filters have an impact in medium and high- frequency damping modes.

The phase-locked loop (PLL) is employed for synchronizing the microgrid to the main grid [13], [14]. The hard off-line tuning of the PLL parameters is the major PLL obstacle. The coupling effect between the PLL and system impedance may lead to the instability issue [15]. A traditional Proportional Integral (PI) controller has been heavily applied to control the DG PWM-inverters [16]. Many research papers show that traditional PI controllers cannot survive against load changes and disturbances in large microgrids [16]-[18]. To overcome this problem, remarkable enhancement is achieved by different computational intelligent techniques, as particle swarm optimization (PSO), bacteria foraging optimization (BFO), and ant colony optimization (ACO) [19]-[22]. Such heuristic methods facilitate the design of MG control. Among them, the PSO has computational efficiency, simplicity, and robustness. So, it is selected to be used to design the microgrid controllers [23], [24].

In this paper, a robust PQ control for an islanded microgrid system against load disturbances is demonstrated. The PQ control method includes two cascade control loops and the PLL. A simple algorithm is presented to tune the parameters of two-PI controllers of the cascade control loops and PLL. To achieve good dynamic performance the maximum overshoot performance index is minimized within the tuning procedure. This mini-max optimization problem is solved using Particle Swarm Approach. The designed PI controller is compared with different tuning techniques. This paper is organized as follows: Section II describes the mathematical model of a microgrid system composed of two DGs and a local load. The PQ control method and the V/F power-sharing method is described. The problem formulation is introduced in section III. In section IV the problem is solved as a min-max optimization problem by the PSO. Comparative results between the proposed design and other tuning methods (conventional, auto tuned, and interior point optimization) is given in section V. Finally, concluding remarks on the proposed approach for controlling islanded microgrid system are specified. 


\section{Mathematical Model}

Consider two PWM inverter-based DGs are feeding the main load through two transmission lines and two transformers as shown in Fig. 1. Each DG PWM inverter is supposed to be connected to a dc power source (Photo Voltaic, PV). Due to an energy storage system (not shown), the dc supply can be assumed constant. The single line diagram of the proposed system is given in Fig. 2.

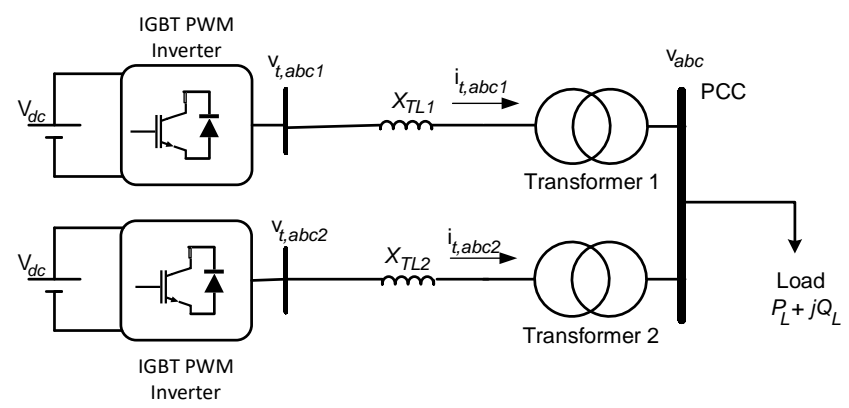

Fig. 1. The schematic diagram for an islanded microgrid system.

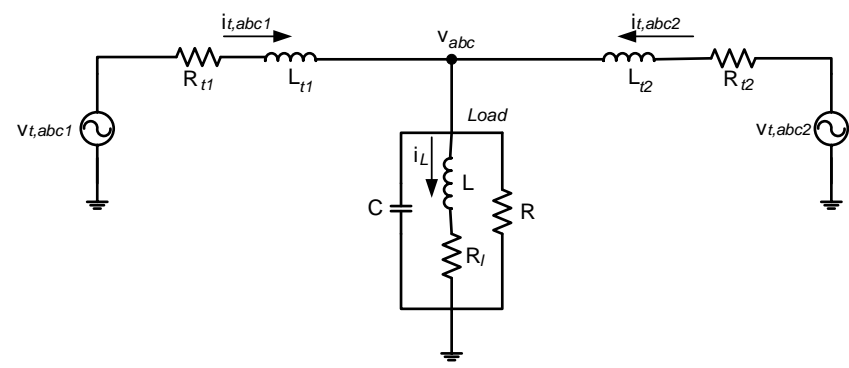

Fig. 2. Single line diagram for the Islanded microgrid system.

The mathematical model of the proposed system in $a b c$ frame [1], [2] is given as:

$$
\begin{gathered}
v_{t, a b c 1}=L_{t 1} \frac{d i_{t, a b c 1}}{d t}+R_{t 1} i_{t, a b c 1}+v_{a b c} \\
v_{t, a b c 2}=L_{t 2} \frac{d i_{t, a b c 2}}{d t}+R_{t 2} i_{t, a b c 2}+v_{a b c} \\
v_{a b c}=L \frac{d i_{L, a b c}}{d t}+R_{l} i_{L a b c} \\
i_{t, a b c 1}+i_{t, a b c 2}=\frac{1}{R} v_{a b c}+i_{L, a b c}+C \frac{d v_{a b c}}{d t}
\end{gathered}
$$

The $a b c$-frame mathematical model in Eq. (1) is transformed to the $d q$-frame [1] to be:

$$
\begin{gathered}
\frac{d v_{d q}}{d t}+j \omega v_{d q}=-\frac{1}{R C} v_{d q}+\frac{1}{C} i_{t, d q 1}-\frac{1}{C} i_{L, d q}+\frac{1}{C} i_{t, d q 2} \\
\frac{d i_{t, d q 1}}{d t}+j \omega i_{t, d q 1}=-\frac{1}{L_{t 1}} v_{d q}-\frac{R_{t 1}}{L_{t 1}} i_{t, d q 1}+\frac{1}{L_{t 1}} v_{t, d q 1} \\
\frac{d i_{L, d q}}{d t}+j \omega i_{L, d q}=\frac{1}{L} v_{d q}-\frac{R t 2}{L_{t 2}} i_{L, d q} \\
\frac{d i_{t, d q 2}}{d t}+j \omega i_{t, d q 2}=-\frac{1}{L_{t 2}} v_{d q}-\frac{R_{t 2}}{L_{t 2}} i_{t, d q 2}+\frac{1}{L_{t 1}} v_{t, d q 2}
\end{gathered}
$$

\section{SYSTEM DESCRIPTION}

The overall block diagram of one of the two DGs proposed system is given in Fig. 3. It consists of two parts; the first part is the $P Q$ control of the PWM inverter-based DG system. The second part is the voltage-frequency powersharing method. The $P Q$ control of the PWM inverter contains two cascaded PI-controllers, the inner controller for the two-current components $(d q)$ and the outer is for the two-power components $(P Q)$.

\section{A. The inner current control loop}

The PWM inverter voltage in $a b c$-frame is denoted as $v_{t, a b c}$, the current is given as $i_{t, a b c}$ and the voltage at the point of common coupling (PCC) is $V_{a b c}$. Referring to the single line diagram in Fig. (2), the dynamics of DG1 is represented by the second line in Eq. (2). Using the traditional $d q$ current control strategy in [7], [6], a simple controller is premeditated for the selected DG system. In this technique, the coupling between $\mathrm{dq}$ axes is removed by using the intermediate control signals $\left(u_{d}\right.$ and $\left.u_{q}\right)$. The control signal $u_{d}$ and $u_{q}$ is stated by Eq. (3) as follows:

$$
\begin{aligned}
\frac{d i_{t, d}}{d t}+\frac{R_{t}}{L_{t}} i_{t, d} & =-\frac{1}{L_{t}} v_{d}+j \omega i_{t, q}+\frac{1}{L_{t}} v_{t, d}=u_{d} \\
\frac{d i_{t, q}}{d t}+\frac{R_{t}}{L_{t}} i_{t, q} & =-\frac{1}{L_{t}} v_{q}-j \omega i_{t, d}+\frac{1}{L_{t}} v_{t, q}=u_{q}
\end{aligned}
$$

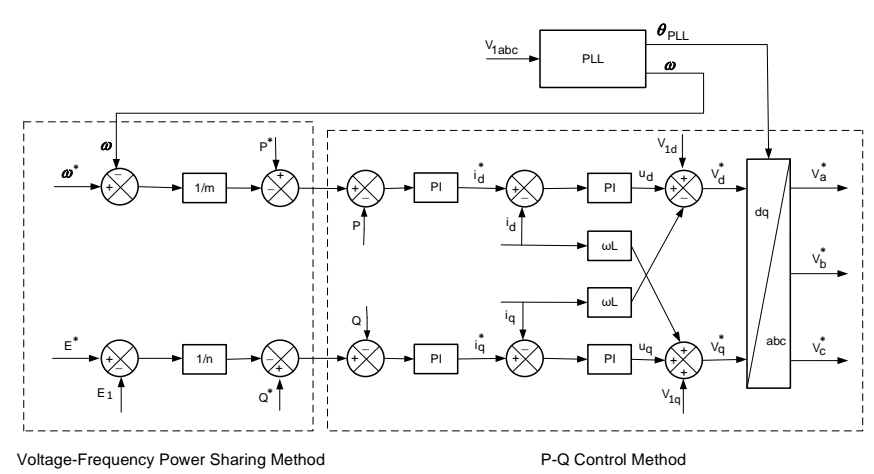

Fig. 3. Overall block diagram of PWM inverter based-DG system.

The block diagram for PI-controllers of the dq current components is given in Fig. 4. The cross-coupling $\left(\omega i_{t, q}\right.$ and $\left.-\omega i_{t, d}\right)$ and the feedforward voltage terms $\left(v_{d}\right.$ and $\left.v_{q}\right)$ must be added after $u_{d}$ and $u_{q}$ are acquired by the controller.

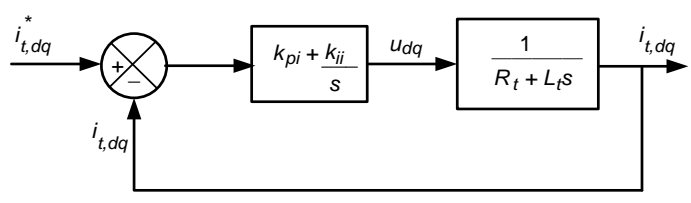

Fig. 4. Block diagram for PI-controllers of dq-current components.

\section{B. Phase-Locked Loop (PLL)}

The $u_{d}$ and $\mathrm{u}_{\mathrm{q}}$ control signals are produced from the PI current controllers of $d q$-current components. The PWM inverter $d q$-axes reference voltage $\left(V_{d}{ }^{*}\right.$ and $\left.V_{q}{ }^{*}\right)$ can be calculated by:

$$
\begin{aligned}
& V_{d}^{*}=u_{d}-j \omega L_{t} i_{t, q}+v_{d} \\
& V_{q}^{*}=u_{q}+j \omega L_{t} i_{t, d}+v_{q}
\end{aligned}
$$

The initiation of the $V_{d}{ }^{*}$ and $V_{q}{ }^{*}$ requires the feedforward voltages $\left(v_{d}\right.$ and $v_{q}$ ) from the PCC voltage and the crosscoupling terms $\left(-\omega L_{t} i_{t, q}\right.$ and $\left.\omega L_{t} i_{t, d}\right)$. Meanwhile, the inputs of the PWM inverter are in $a b c$ voltages, so the $d q$ axis voltages have to be converted into $a b c$ voltages. Since 
the dq-reference frame is based on the space vector of the PCC voltage, the space vector of the PWM inverter voltage will be:

$$
\vec{V}=\left(V_{d}+j V_{q}\right) e^{j \theta}
$$

where $\theta$ is the PCC voltage space vector angle. The inputs to the PLL are three-phase voltages. These voltages will be converted to $d q$-axis voltages using the PLL angle $\left(\theta_{p l l}\right)$. The feedback loop with the help of the PLL PI-controller is pushing the q-axis voltage to zero. Fig. 5 shows the block diagram of the PLL control loop.

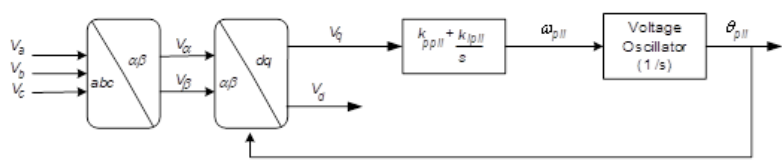

Fig. 5. Block diagram of the PLL control loop.

\section{The outer $P Q$ control loop}

It is recommended that the outer control loop of the $P Q$ control method to be too slow compared to the inner current control loop to reveal the dynamic variations. The simplified block diagram of the outer control loop is given in Fig. 6. Since the $d$-axis of the $d q$-reference frame is aligned with the PCC voltage, the per unit real and reactive power can be given in Eq. (6), where $V_{l}$ is the magnitude of the per-phase voltage of the PCC.

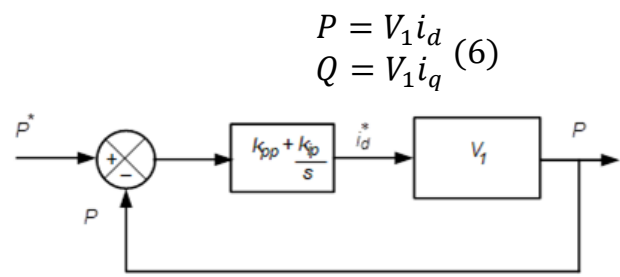

Fig. 6. The outer loop block diagram for PQ-control method.

\section{V/F power-sharing}

The Droop controls that are used in synchronous generators can also be applied in the PWM inverter. The $\mathrm{V} / \mathrm{F}$ droop control equation can be expressed in Eq. (7) as:

$$
\begin{aligned}
P^{*} & =-\frac{1}{m} P+\left(\omega^{*}-\omega\right) \\
Q^{*} & =-\frac{1}{n} Q+\left(E^{*}-E\right)
\end{aligned}
$$

where $m$ and $n$ are the droop coefficients, The PLL is employed to obtain the PCC voltage as well as its frequency.

\section{PROBLEM SOLUTION}

As has been shown from the previous section that we have three-PI controllers to be designed and tuned. The first controller for the inner current control loop, the second controller for the PLL and the third controller for the outer $P Q$ control loop. Traditional techniques as Ziegler and Nichols technique can be used to determine the gains of the
three-PI controllers but there is no guarantee that the obtained controllers will provide the good performance of minimal overshoot. In the proposed control system, the PSO is used to assure a robust minimal overshoot response for the three-PI controllers under different dynamic cases. To evaluate the superiority of system dynamic performance the maximum overshoot control parameter should be minimized within the tuning process. This mini-max optimization problem is resolved using PSO presented thereafter.

\section{A. Mini-max optimization problem}

Problem: Given the systems in Figs. 4, 5 and 6 find three PI-controllers parameters to achieve minimum overshoot response. In other words, to stabilizes these systems with minimal overshoot response over the working range. These robust minimal-overshoot controllers can be attained by solving the next mini-max optimization problem:

$$
\begin{aligned}
& \underset{k_{p}, k_{i}}{\operatorname{minimize} J} \\
& =\max \left(\frac{\Delta X(t)_{\max }-\Delta X_{S S}(t)}{\Delta X_{S S}(t)}\right) \forall \text { operating regimes }
\end{aligned}
$$

where $J$ stands for the worst overshoot over the operating regimes, $\Delta X(t)_{\max }$ and $\Delta X(t)_{s s}$ represent respectively the maximum and steady-state values of the variable to be controlled in the three-control loops.

Note that selecting the maximum overshoot as a candidate for the objective function of the proposed design has several benefits. Because:(1) reducing the overshoot is equivalent to increasing the damping ratio or enhancing system stability and consequently reducing the settling time, and (2) if maximizing the damping ratio were selected instead, the resulting response will be non-oscillatory but the settling time will be large.

\section{B. Particle Swarm Optimization (PSO)}

The PSO is an evolutionary-based non-linear optimization method. This method is motivated by biological inspiration and is based on the natural evolution of populations to the natural selection principle of Darwin "Survival of the Fittest". PSO is an innovative technique of optimization [23]. It is a multi-representative search technique that follows its assessment to the increasing movement of a flock of birds (representative, particle) looking for food. Each bird navigates to the search space seeking for the global minimum (or maximum) search space. The PSO technique is computationally simple as the gradient calculation is not required. Also, there is no need for the objective function to be convex. It is a stochastic method of optimization with a big number of representatives, so being stuck at a local minimum is sometimes doubtful.

While the PSO algorithm members are searching the space, two places are remembered by each member. The first is the position of the representative's (self-best) best point. The second is the position of the best point discovered among all (group-best) representatives. The equations which handle each representative's motion are [24]:

$$
\begin{gathered}
\vec{S}_{\text {new }}=[\vec{S}+\vec{v}]_{\text {old }} \\
\left.\vec{v}\right|_{\text {new }}=\left[\omega \vec{v}+\operatorname{ar}(0,1)\left(\vec{S}_{\text {self-best }}-\vec{S}\right)+\operatorname{br}(0,1)\left(\vec{S}_{\text {group-best }}-\vec{S}\right)\right]_{\text {old }}
\end{gathered}
$$


where

$(\vec{S})$ is a position vector of a single particle,

$(\vec{v})$ is the velocity of this particle,

$(a, b)$ are two scalar parameters of the algorithm,

$(\omega)$ is an inertia weight,

$r(0,1)$ is a uniform random number between 0 and 1 .

The group-best is the best solution among all particles. Also, the self-best is the best solution detected by the current particle. A maximum velocity $\left(\vec{v}_{\max }\right)$ that cannot be exceeded may also be required. The parameters of the three PI controllers are adjusted using PSO by minimizing Eq. (8). To achieve the optimization purpose, proper fine-tuning of the PSO parameters is desired [24].

\section{Current controller design using PSO}

Referred to Fig. 4, the two-gains ( $k_{p i}$ and $k_{i i}$ ) of the PI controller in the inner current control loop are adjusted by applying PSO using the objective function in Eq. (8). The closed-loop overall transfer function for the current control loop is given in Eq. (10).

$$
G_{\text {current_c.l }}=\frac{s+\frac{k_{i i}}{L_{t}}}{s^{2}+\left(\frac{R_{t}+k_{p i}}{L_{t}}\right) s+\frac{k_{i i}}{L_{t}}}
$$

Toward the optimization goal, a proper selection of the PSO parameters is desired [22]. Table 1 shows the parameters of PSO that provide the best results for the inner current control loop. The two-gains $\left(k_{p i}\right.$ and $\left.k_{i i}\right)$ of the PI controller are randomly initialized. Fig. 7a shows the global best value of the objective function against the number of iterations. The PI controller gains selected by the PSO algorithm for the minimal overshoot are given in Table (2).

\section{Phase-Locked Loop controller design using the PSO}

In the inner current controller loops, the $u_{d q}$ control signal will be generated, while the PWM inverter dq-axis reference voltages $V_{d q}{ }^{*}$ is computed by Eq. (4). The PWM of the voltage source inverter has to be in the $a b c$-reference frame, therefore the angle generated from the PLL $\left(\theta_{P L L}\right)$ is used to convert the voltage signals from $d q$-axis to $a b c$-reference frame as shown in Fig. 5.

The space vector of the converter voltage is given in Eq. (5), The PLL model specified in Fig. 5 is linearized and the PLL is designed to have a bandwidth of $100 \mathrm{~Hz}$ [25]. The PI gains designed from this bandwidth are used as an initial guess for the PLL min-max optimization function. The closed-loop overall transfer function for the PLL is illustrated in Eq. (11).

$$
G_{P L L_{-} c . l}=\frac{s+\frac{k_{i p l l}}{k_{p p l l}}}{s^{2}+k_{p p l l} s+k_{i p l l}}
$$

The two-gains ( $k_{p p l l}$ and $k_{i p l l}$ ) of the PI controller are randomly initialized. Fig. $7 \mathrm{~b}$ displays the global best value of the objective function versus the number of iterations. The PI controller gains designated by the PSO algorithm for the minimal overshoot are provided in Table 2.

\section{E. $P Q$ controller design using $P S O$}

The outer control loop is constructed to be very slow compared to the inner control loop to reveal the dynamic changes. Eq. (6) shows that the per unit real and reactive power in the $d q$-reference frame are aligned with the PCC voltage. Fig. 6 shows the outer loop block diagram for the PQ-control method. The closed-loop transfer function for the $\mathrm{P}$ (real power) control loop is given in Eq. (12).

$$
G_{P-c . l}=\frac{\frac{k_{p p}}{k_{i p}} s+1}{\left(\frac{1}{V_{1} k_{i p}}+\frac{k_{p p}}{k_{i p}}\right) s+1}
$$

The bandwidth is $1 / \tau$ where $\tau=\frac{1}{V_{1} k_{i p}}+\frac{k_{p p}}{k_{i p}}$. The twogains $\left(k_{p p}\right.$ and $\left.k_{i p}\right)$ of the PI controller are randomly initialized. Fig. 7c demonstrates the global best value of the objective function against the number of iterations. The PI controller gains obtained by the PSO algorithm to achieve the minimal overshoot response are presented in Table 1.
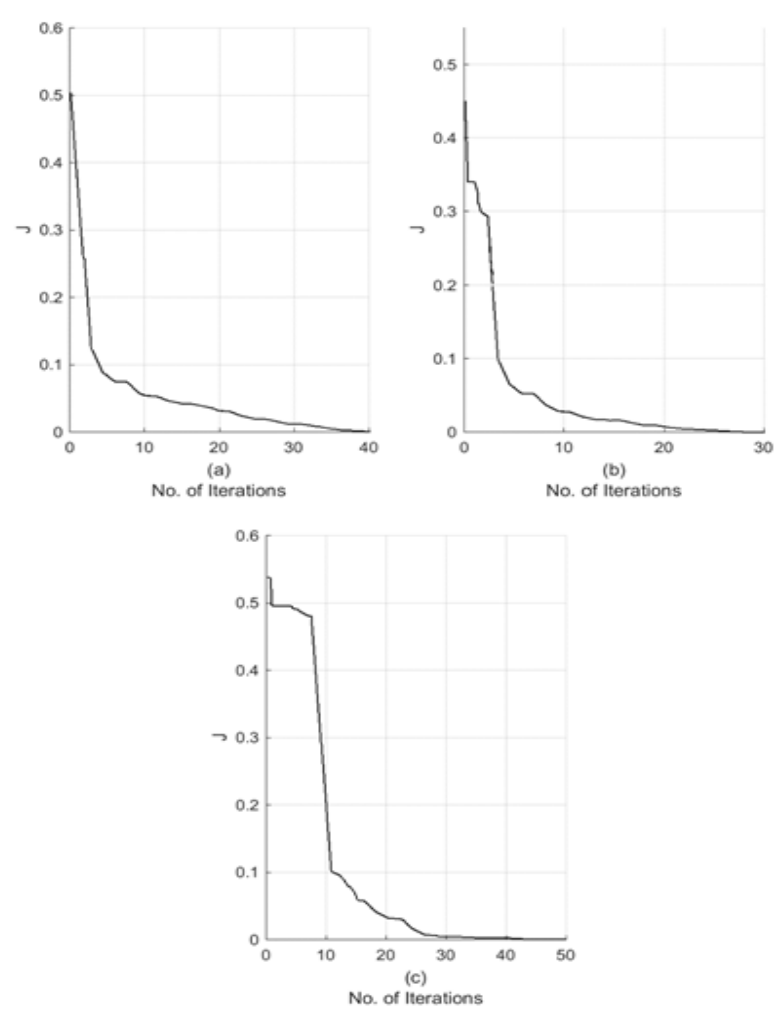

Fig. 7. Objective function (global best values) against the number of iterations for; (a) PI current controller, (b) PLL, and (c) PQ control loop.

TABLE 1: PSO PARAMETERS FOR THE THREE PROPOSED PI CONTROLLERS

\begin{tabular}{|c|c|c|c|}
\hline $\begin{array}{c}\text { PSO } \\
\text { parameters }\end{array}$ & $\begin{array}{c}\text { Current } \\
\text { control loop }\end{array}$ & $\begin{array}{c}\text { Phase-Locked } \\
\text { loop (PLL) }\end{array}$ & PQ control loop \\
\hline $\begin{array}{c}\text { No. of swarm } \\
\text { birds (particles) }\end{array}$ & 30 & 30 & 30 \\
\hline $\begin{array}{c}\text { Particle } \\
\text { dimension }\end{array}$ & $2\left(k_{p i}, k_{i i}\right)$ & $2\left(k_{p-p l}, k_{i-p l l}\right)$ & $2\left(k_{p p}, k_{i p}\right)$ \\
\hline $\begin{array}{c}\text { Max. particle } \\
\text { speed, Vmax }\end{array}$ & 0.09 & 0.12 & 0.37 \\
\hline$\omega, \mathrm{a}, \mathrm{b}$ & $0.55,0.5,0.5$ & $0.55,0.45,0.47$ & $0.65,0.74,0.78$ \\
\hline
\end{tabular}

Note that designing the three controllers in a decoupled fashion (consequently the design of one will not affect the others) is justified because: (1) in the cascade control, the 
controller of the inner current loop is designed to provide much faster response than that of the outer loop, and (2) the third controller, PQ controller, is entirely decoupled from the cascade control.

\section{RESULTS}

The microgrid system in Fig. 1 is implemented using the MATLAB software package. The system is consisting of two DGs. Each DG unit has its own PWM inverter as shown in Fig. 1. The parameters of the microgrid system are given in Table 3. There are three control loops in each DG unit (current loop, PQ loop, and the PLL). The PI controller is used in the three-control loops. The proposed PI tuning is compared with three tuning methods: (1) the conventional Ziegler-Nichols, (2) auto-tuning, and (3) the interior-point optimization [26]. The resulting PI using the three methods+ the proposed one are given in Table 2 .

A. Comparing the Proposed Design with the Conventional PI for the Three Loops

The PLL shown in Fig. 5 is designed by the proposed PI and the traditional Ziegler and Nichols. In Fig. 8, at $t=0.1$ seconds, the proposed PLL is tested against the frequency of the input signal increases from $314 \mathrm{rad} / \mathrm{s}(50 \mathrm{~Hz})$ to 628 $\mathrm{rad} / \mathrm{s}(100 \mathrm{~Hz})$. It shows that the proposed PLL can correctly identify the frequency within 0.02 seconds, while the traditional PLL takes about 0.08 seconds as in the top of Fig. 8. Moreover, in the bottom part of Fig. 8, it is evident that the proposed -PLL has a minimal overshoot of $0.12 \%$ while in the traditional PLL it has $4.2 \%$ overshoot.

The PQ cascade control technique is tested against real power $(P)$ and reactive power $(Q)$ changes. At $t=0.2$ seconds, the real power is stepped up from $0.2 \mathrm{pu}$ to $1 \mathrm{pu}$, and at $t=0.3$ seconds the reactive power is stepped up from $0.1 \mathrm{pu}$ to $0.5 \mathrm{pu}$. Fig. 9 shows that the proposed $P Q$ controller makes the DG output real power and reactive power track the reference with a fast and dead-beat response. The conventional PQ controller is given in the same figure to do a comparison between the two controllers. The proposed PQ-controller has a faster response with rise time $t_{r}=0.005$ second and settling time $t_{s}=0.01$ second, while the conventional PI has $t_{r}=0.23$ second and $t_{s}=0.39$ second. The proposed and the conventional PQ-controller has a \%overshoot P.O. $=0.04 \%$, and $0.22 \%$ respectively. Moreover, the Current controller can be also tested in this case. The middle part from Fig. 8 shows how the $d q$-current components respond to the step changes in power in the proposed controller and the traditional one. It shows that the proposed current controller gives a dead-beat fast response compared to the conventional one.

The power-sharing between the two DG units in the microgrid is illustrated. In this case, initially the power is shared between the $\mathrm{DG}_{1}$ and $\mathrm{DG}_{2}$ equally, then each $\mathrm{DG}$ shares half the real power $(0.5 \mathrm{pu})$, while the total reactive power to the load is $0.15 \mathrm{pu}$., each DG will share $0.075 \mathrm{pu}$. At $\mathrm{t}=0.5 \mathrm{~s}$, the droop coefficients $\frac{m_{1}}{m_{2}}=\frac{n_{1}}{n_{2}}=\frac{1}{2}$, which indicates there is a load change, DG2 will takes $\frac{2}{3}$ of the power change share while the DG1 will take $\frac{1}{3}$ of the share.
The PCC voltage is kept at $1 \mathrm{pu}$. The decrease of the load resistance from $114 \Omega(1.5 \mathrm{pu})$ to $76 \Omega(1 \mathrm{pu})$ makes the real power consumption increased from $1 \mathrm{pu}$ to $1.333 \mathrm{pu}$. For the $0.333 \mathrm{pu}$ real power consumption change, $0.222 \mathrm{pu}$ will be generated by $\mathrm{DG}_{2}$ and 0.111 pu will be generated by $\mathrm{DG}_{1}$. Therefore, the steady-state value of the real power of $\mathrm{DG}_{2}$ $\left(P_{2}\right)$ will be $0.7222 \mathrm{pu}$, and the real power of $\mathrm{DG}_{1}\left(P_{1}\right)$ will be $0.6111 \mathrm{pu}$. The reactive power of $\mathrm{DG}_{1}\left(Q_{l}\right)$ and $\mathrm{DG}_{2}\left(Q_{2}\right)$ will be changed to $0.1 \mathrm{pu}$ and $0.05 \mathrm{pu}$ respectively. The system frequency $(\Delta \omega)$ will be reduced, calculated from the droop coefficients as:

$$
\Delta \omega=\frac{\Delta P}{m_{1}+m_{2}}=\frac{0.3333}{0.04+0.08}=2.775 \frac{\mathrm{rad}}{\mathrm{s}}
$$

The above calculations are confirmed by the results shown in Fig. 10. In Fig. 11 it shows the $V_{a b c}$ at the PPC is given.

TABLE 2: THE GAINS VALUES FOR THE THREE LOOPS -PI CONTROLLERS TUNED BY DIFFERENT METHODS

\begin{tabular}{|c|c|c|c|c|c|c|c|c|}
\hline \multirow{2}{*}{$\begin{array}{c}\text { PI } \\
\text { Controller } \\
\text { for }\end{array}$} & \multicolumn{2}{|c|}{$\begin{array}{c}\text { Conventional } \\
\text { tuning }\end{array}$} & \multicolumn{2}{c|}{ Auto-Tuning } & \multicolumn{2}{c|}{$\begin{array}{c}\text { Interior point } \\
\text { tuning }\end{array}$} & \multicolumn{2}{c|}{ Proposed tuning } \\
\cline { 2 - 9 } & $k p$ & $k i$ & $k p$ & $k i$ & $k p$ & $k i$ & $k p$ & $k i$ \\
\hline $\begin{array}{c}\text { Current } \\
\text { control } \\
\text { loop }\end{array}$ & 6.66 & 18949.6 & 15.66 & 1708.4 & 15.21 & 1826.6 & 27.34 & 2025.4 \\
\hline PLL & 4.83 & 0.019 & 10.74 & 0.059 & 24.6 & 0.0112 & 29.51 & 0.0082 \\
\hline $\begin{array}{c}\text { PQ } \\
\text { control } \\
\text { loop }\end{array}$ & 0.00021 & 0.532 & 0.0092 & 0.842 & 0.0084 & 3.47 & 0.0217 & 25.03 \\
\hline
\end{tabular}

TABLE 3: THE PARAMETERS OF THE MICROGRID SYSTEM

\begin{tabular}{|c|c|c|}
\hline Item & Quantity & Value \\
\hline DG1 & $R_{t l}$ & $1.5 \mathrm{~m} \Omega$ \\
& $L t 1$ & $300 \mu \mathrm{H}$ \\
\hline DG2 & $R_{t l}$ & $6 \mathrm{~m} \Omega$ \\
& $L_{t l}$ & $900 \mu \mathrm{H}$ \\
\hline PWM & VSC rated Power & $S_{\text {base }}=2.5 \mathrm{MVA}$ \\
Inverters & Terminal Voltage (line-line) & $V_{\text {base }}=600 \mathrm{~V}$ \\
& Switching Frequency & $2.5 \mathrm{kHz}$ \\
\hline Load & $R$ & $76 \Omega$ \\
& $L$ & $112 \mathrm{mH}$ \\
& $C$ & $63 \mu \mathrm{F}$ \\
& $R_{l}$ & $0.36 \Omega$ \\
\hline others & System frequency & $50 \mathrm{~Hz}$ \\
& Vdc (DC bus voltage) & $1200 \mathrm{~V}$ \\
\hline
\end{tabular}

The proposed design is also compared with auto-tuning and interior-point techniques as follows.

B. Comparing the proposed design with the auto-tuned $P I$

The proposed controller is tested for active and reactive power change as in case (2) and compared with the Matlab auto-tuned PI as shown in Fig. 12. The auto tuned PI parameters for the inner current loop, PLL and PQ control loop are given the Table 2. Fig. 12 shows that the proposed PQ controller provides the DG output real power and reactive power tracking the reference with a fast and deadbeat response. It outperforms the response using the conventional PI and auto-tuned PI.

C. Comparing the proposed design with the interiorpoint tuned PI

It is evident that the proposed PI outperforms the PI tuned by the interior-point method Fig. 13. 


\section{Case (1): PLL loop}

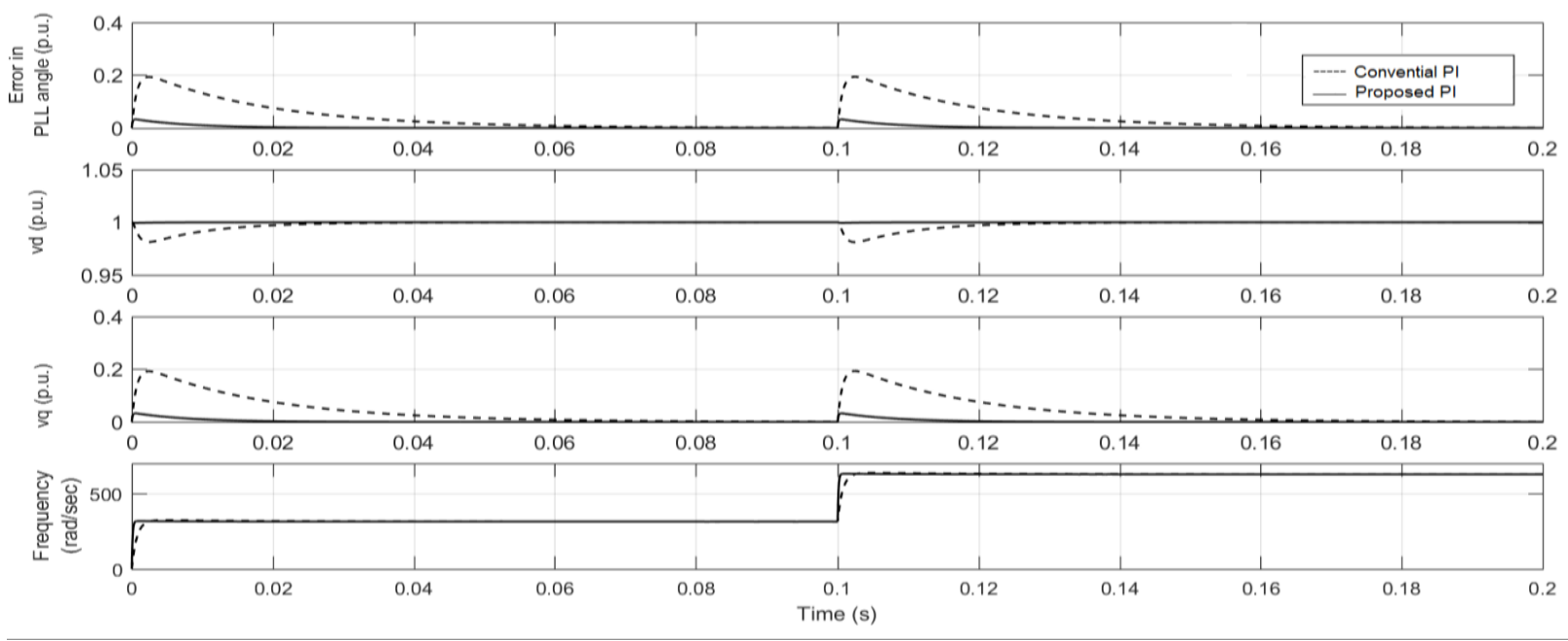

Fig. 8. A Step change in the frequency of the input signal from $314 \mathrm{rad} / \mathrm{s}$ to $628 \mathrm{rad} / \mathrm{s}$.

\section{Case (2): $P Q$ loop}
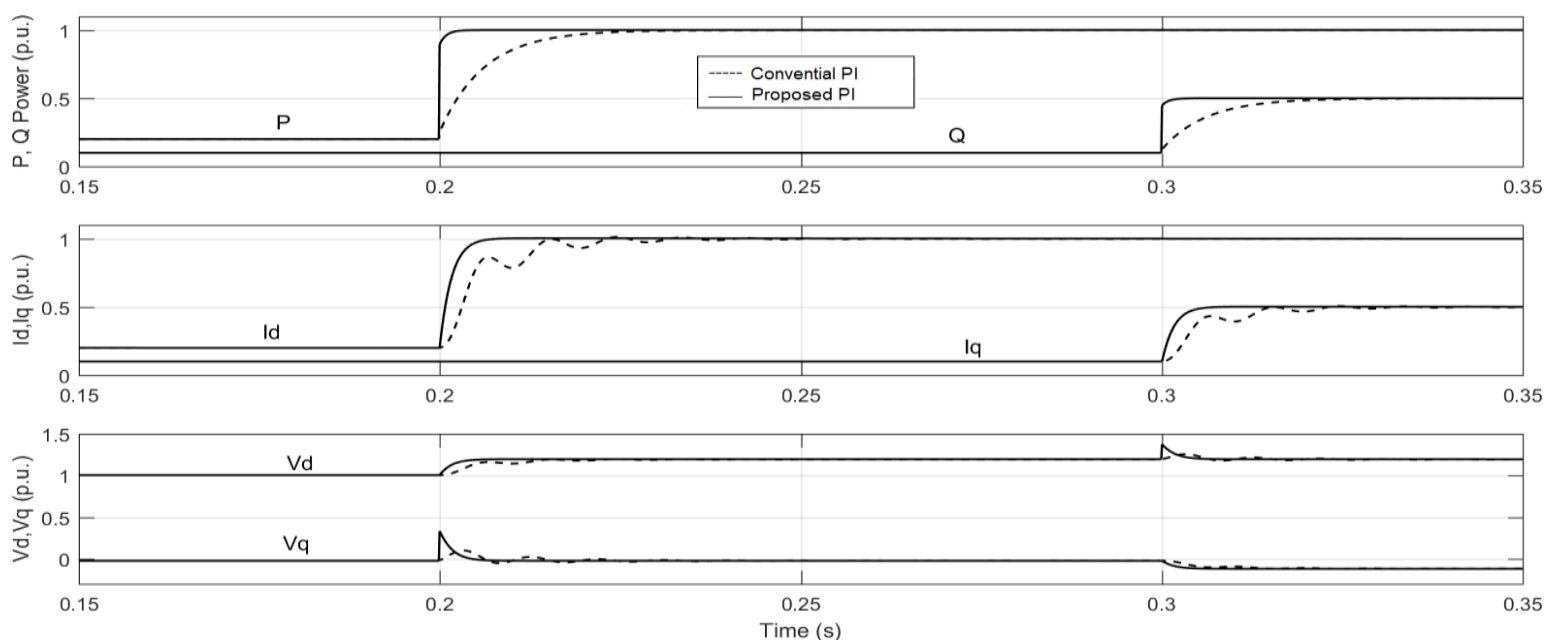

Fig. 9. PQ control loop against step changes in real and reactive power.

\section{Case (3): Power sharing}
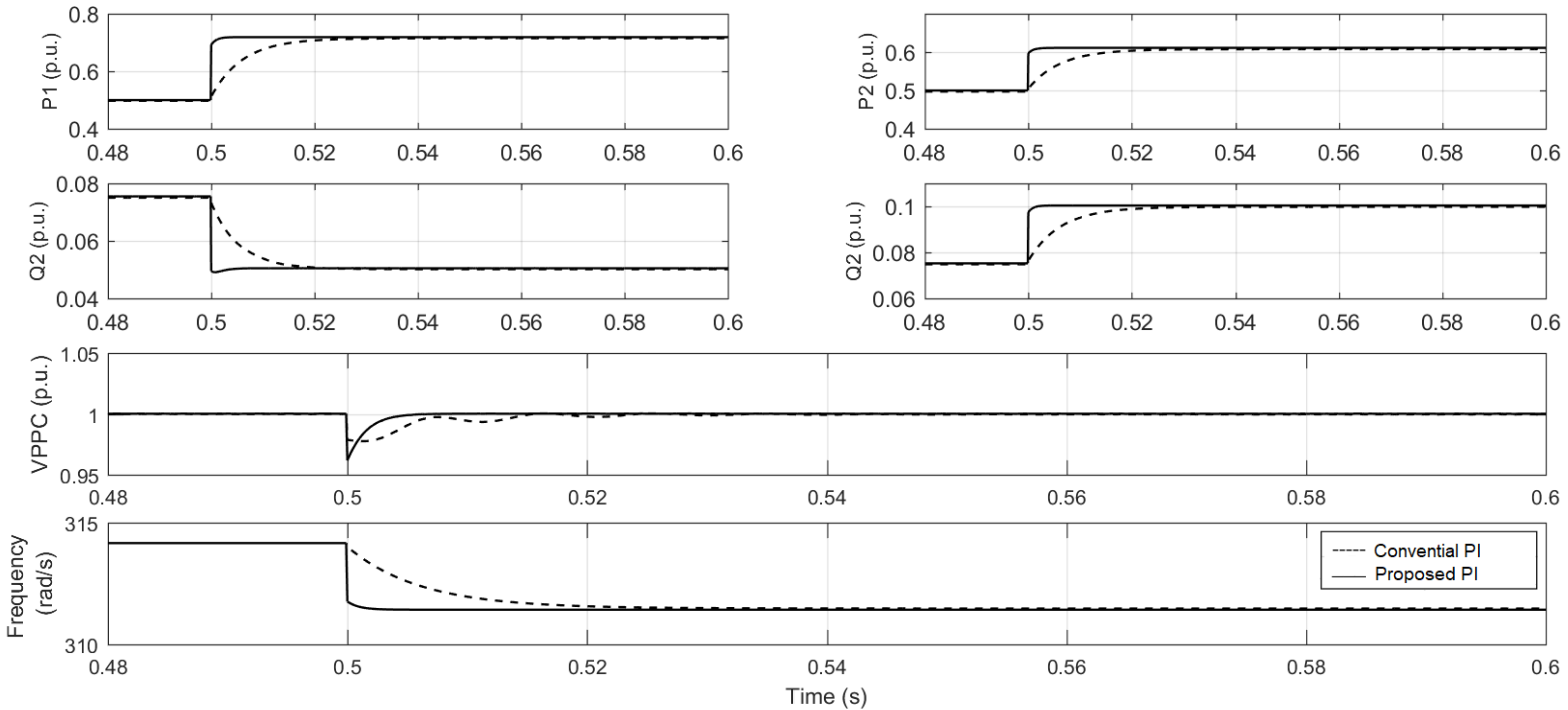

Fig. 10. The real and reactive power during power-sharing between the two DGs. 


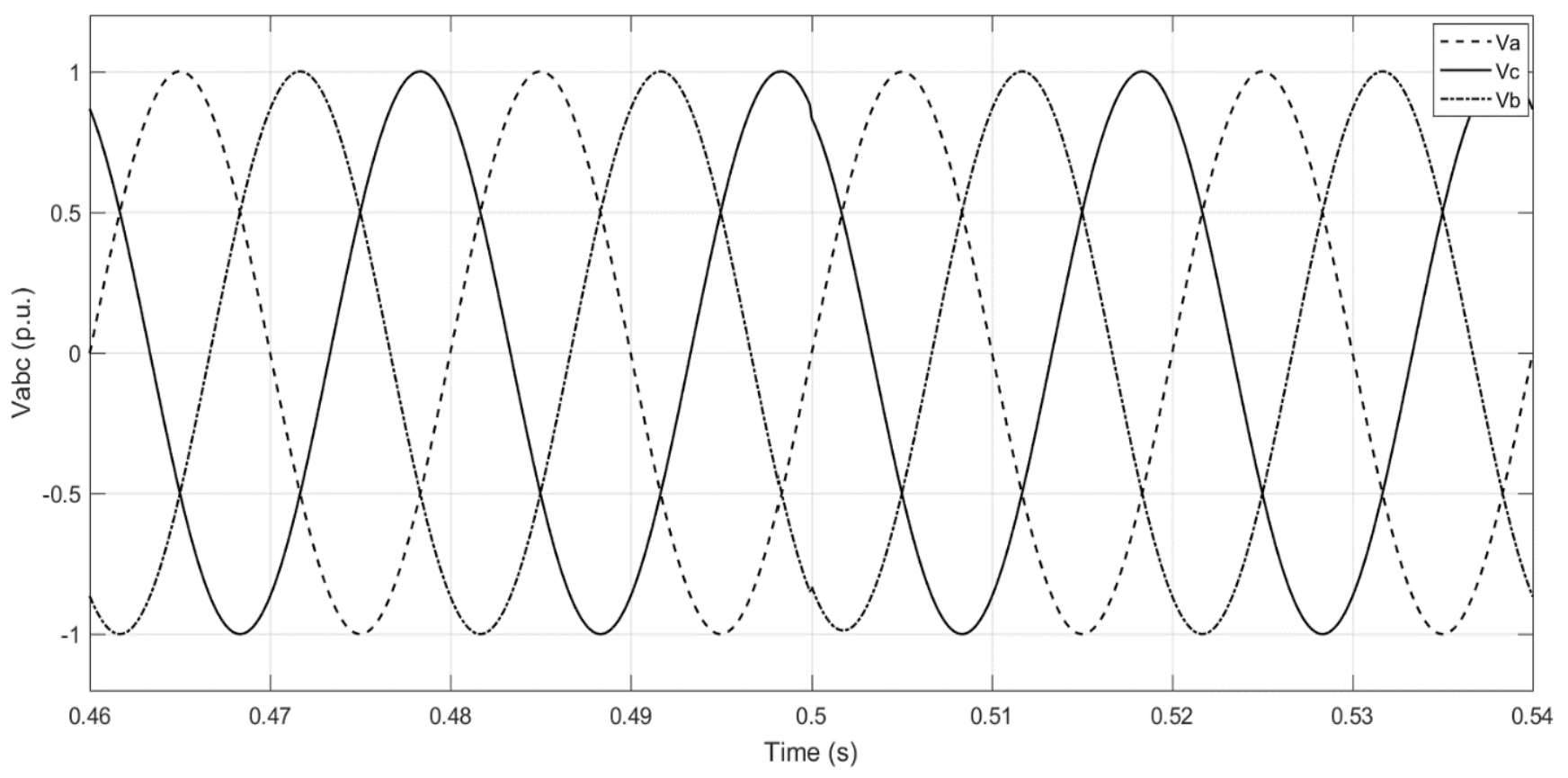

Fig. 11. The $\mathrm{V}_{\mathrm{abc}}$ at the PPC during the power-sharing between the two DGs.
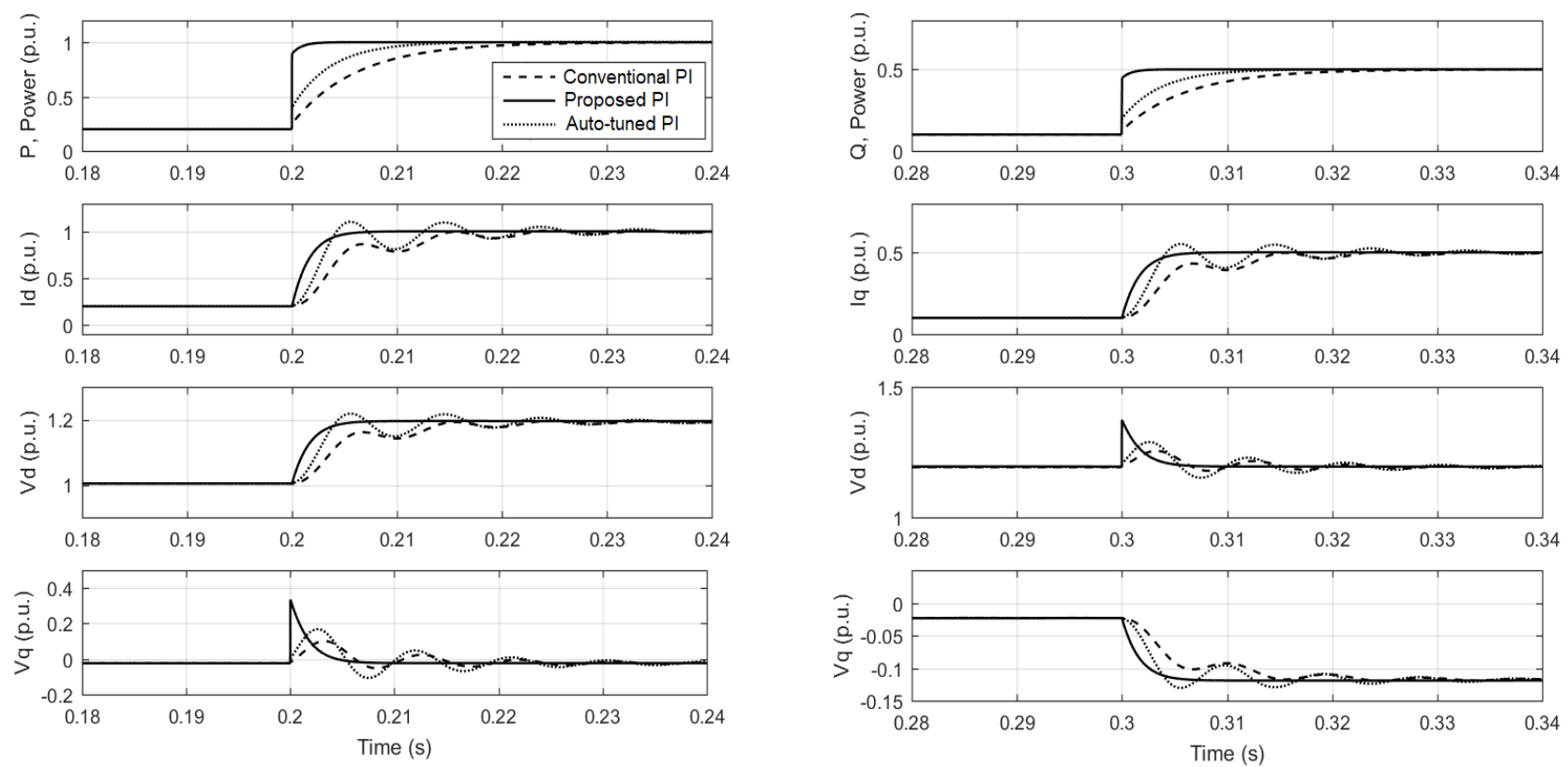

Fig 12. Proposed, conventional and auto-tuned PI-PQ controllers against step change in real and reactive power. 

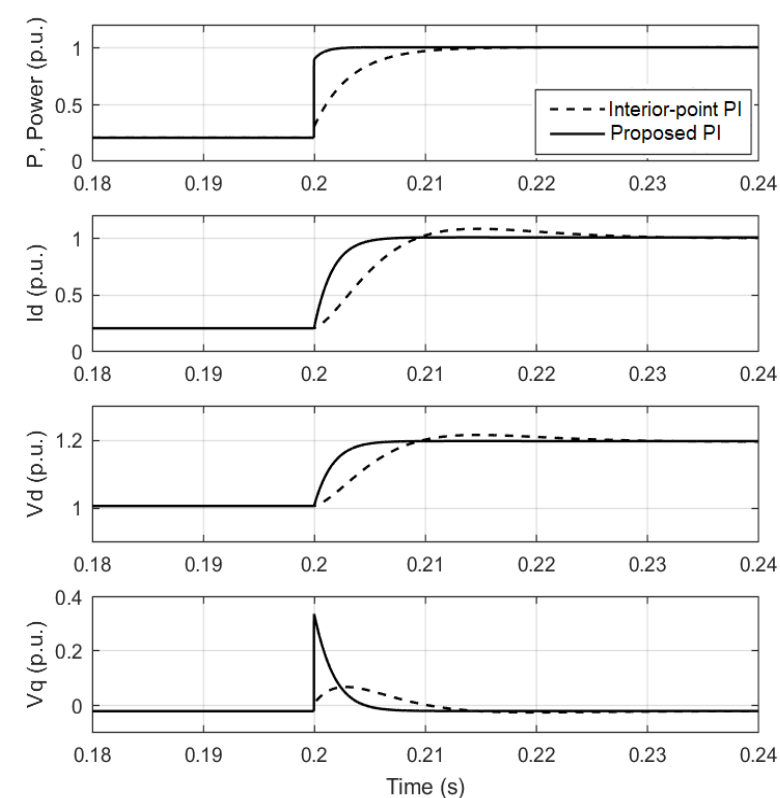
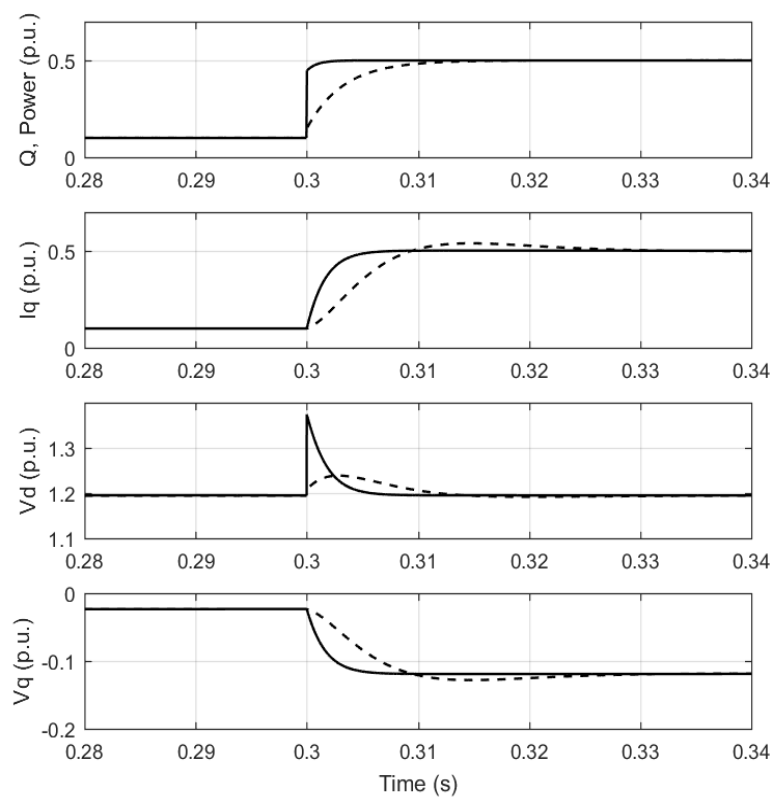

Fig. 13. Proposed and interior-point PI-PQ controllers against step change in real and reactive power.

\section{CONCLUSION}

In this paper, an islanded microgrid system composed of two Distributed Generation (DG) units have been modelled, studied and evaluated. The PQ control method for microgrid system includes two cascade control loops. The inner loop is for the dq-currents and the outer loop is for the real and reactive powers (P and $\mathrm{Q})$. The Phase-Locked Loop (PLL) has to be well designed to guarantee overall system stability. The controllers' gains and the PLL design for the microgrid system are tuned by using Particle Swarm Optimization (PSO). The proposed objective function to be minimized using PSO his selected as the maximum overshoot. Results illustrate superior performance with competent damping characteristics for the given microgrid system. A comparative study between the proposed tuning with others are presented. It reveals the advantage of the proposed technique.

\section{REFERENCES}

[1] M. A. Hassan, M. Y. Worku, and M. A. Abido, "Optimal design and real time implementation of autonomous microgrid including active load", Energies, 2018, 11, 1109; doi:10.3390/en11051109.

[2] I. A. Hiskens, and E. M. Fleming, "Control of inverter-connected sources in autonomous microgrids", 2008 American Control Conference, Seattle, Washington, USA, June 11-13, 2008, pp. 586:590.

[3] F. Habibi, A H. Naghshbandy, H. Bevrani, "Robust voltage controller design for an isolated microgrid using Kharitonov's theorem and Dstability concept", Electrical Power and Energy Systems, 2013, 44, pp. 656-665.

[4] M. Babazadeh , H. Karimi, "Robust decentralized control for islanded operation of a microgrid", 2011 IEEE Power and Energy Society General Meeting, San Diego, CA, USA, 24-29 July 2011, pp. 1-8.

[5] J.A.P. Lopes, C.L. Moreira, and A.G. Madureira, "Defining control strategies for MicroGrids islanded operation", IEEE Transactions on Power Systems, Volume: 21, Issue: 2, 2006, pp: 916 - 924.
[6] S. Yao, C. Li, Yun Teng, X. Yang, and J. Ren, "Research on Reactive Power and Voltage Optimization Control Method Based on Active Distribution Network", 2016 International Conference on Smart City and Systems Engineering (ICSCSE), 25-26 Nov. 2016, Hunan, China.

[7] D. Olivares, A. Mehrizi-Sani; A.H. Etemadi, C.A. Cañizares, R. Iravani, M. Kazerani, A.H. Hajimiragha, O. Gomis-Bellmunt, M. Saeedifard; R. Palma-Behnke; et al. Trends in microgrid control. IEEE Trans. Smart Grid 2014, 5, 1905-1919.

[8] K. Tan; X. Peng; P. So; Y. Chu; M. Chen. Centralized control or parallel operation of distributed generation inverters in microgrids. IEEE Trans. Smart Grid 2012, 3, 1977-1987.

[9] Y. Wang; X. Wang; Z. Chen; F. Blaabjerg. Distributed optimal control of reactive power and voltage in islanded microgrids. IEEE Trans. Ind. Appl. 2017, 53, 340-349.

[10] N. Bottrell; M. Prodanovic; T. Green. Dynamic stability of a microgrid with an active load. IEEE Trans. Power Electron. 2013, 28, 5107-5119.

[11] J. He; Y. Li. An enhanced microgrid load demand sharing strategy. IEEE Trans. Power Electron. 2017, 27, 3984-3995.

[12] Y. Han; H. Li; P. Shen; E. Coelho; J. Guerrero. Review of active and reactive power sharing strategies in hierarchical controlled microgrids. IEEE Trans. Power Electron. 2017, 32, 2427-2451.

[13] H. A. Hamed, A. F. Abdou, E. H.E. Bayoumi, and E. E. EL-Kholy," A Fast Recovery Technique for Grid-Connected Converters After Short Dips Using a Hybrid Structure PLL", IEEE Transactions on Industrial Electronics, Vol. 65, No. 4, April 2018, pp. 3056 - 3068.

[14] H. A. Hamed, A. F. Abdou, E. Bayoumi, E. E. EL-Kholy," Frequency Adaptive CDSC-PLL Using Axis Drift Control Under Adverse Grid Condition," IEEE Transactions on Industrial Electronics, Vol. 64, No. 4, April 2017, pp. 2671-2683.

[15] D. Dong; B. Wen; D. Boroyevich; P. Mattavelli; Y. Xue. Analysis of phase-locked loop low-frequency stability in three-phase gridconnected power converters considering impedance interactions. IEEETrans. Ind. Electron. 2015, 62, 310-321.

[16] D. Marx; P. Magne;N. Mobarakeh; S. Pierfederici; B. Davat , "Large signal stability analysis tools in dc power systems with constant power loads and variable power loads-A review", IEEE Trans. Power Electron. 2012, 27, 1773-1787.

[17] D. Karimipour; F. Salmasi. Stability Analysis of AC Microgrids with Constant Power Loads Based on Popov's Absolute Stability Criterion. IEEE Trans. Circuits Syst. II 2015, 62, 696-700.

[18] X. Guo; Z. Lu; B.Wang; X. Sun; L. Wang; J. Guerrero. Dynamic phasors-based modeling and stability analysis of droop-controlled inverters for microgrid applications. IEEETrans. SmartGrid 2014, 5, 2980-2987. 
[19] S. Khorramabadi; A. Bakhshai. Critic-based self-tuning PI structure for active and reactive power control of VSCs in microgrid systems. IEEE Trans. Smart Grid 2015, 6, 92-103.

[20] M.Awadallah, E.H.E.Bayoumi and H.M.Soliman, "Adaptive Deadbeat Controllers for BLDC Drives using PSO and ANFIS Techniques", Journal of Electrical Engineering, Vol 60, No. 1, pp. 311, 2009.

[21] H.M.Soliman, E.H.E.Bayoumi and M.F.Hassan, "Power System Stabilizer Design for Minimal Overshoot and Control Constraint Using Swarm Optimization", Electric Power Components and Systems, Vol.37, No.1, pp.111-126, Jan 2009.

[22] E.H.E. Bayoumi and F. Salem, "PID Controller for Series-Parallel Resonant Converters Using Bacterial Foraging Optimization", Electromotion Scientific Journal, Vol.19, no. 1-2, pp. 64-78, JanuaryJune 2012.

[23] J. Kennedy; R. Eberhart. Particle swarm optimization. In Proceedings of the IEEE International Conference on Neural Networks, Perth, Western Australia, 27 November-1 December 1995; Volume 4, pp. 1942-1948.

[24] E.H.E.Bayoumi and H.M.Soliman, "PID/PI tuning for Minimal Overshoot of PM Brushless DC Motor Drive Using Swarm Optimization", Electromotion Scientific Journal, Vol 14, No.4, pp. 198-208, Oct-Dec 2007.

[25] E.H.E.Bayoumi, "A Novel Approach to Control an unbalanced three phase induction motor". Electromotion Scientific Journal, Vol 12, No.4, pp.213-222, Oct.-Dec., 2005.

[26] S. S. Rao, "Engineering Optimization Theory and Practice "4e, JOHN WILEY \& SONS, INC 2009. 